\title{
Recovery of sertoli cells by Allium cepa in Toxoplasma gondii infected rats
}

\author{
Arash Khaki ${ }^{1}$, Elham Ghadamkheir ${ }^{2}$, Elaheh Ouladsahebmadarek ${ }^{1}$, Amir Hagighi $^{3}$, \\ Shahin Ahmadi ${ }^{1}$. \\ 1Women's Reproductive Health Research Center, Tabriz University of Medical Sciences, Tabriz, Iran. \\ ${ }^{2}$ Faculty of Medicine Tabriz Branch, Islamic Azad University, Tabriz, Iran. \\ ${ }^{3}$ Department Of Radiology And Nuclear Medicine Keck School of Medicine UNIVERSITY OF Southern \\ California Los Angeles, California-USA.
}

\begin{abstract}
Accepted 10 July, 2012
Toxoplasma gondii is a protozoan parasite that is globally widespread and it affects men and animals. We investigated the effect of allium cepa (onion juice) on sperm parameters, testestrone level in male rats was experimentally infected by $T$. gondii. Wistar male rats $(n=40)$ were allocated into four groups: control group $(n=10), T_{1}$ group that received tachyzoites of $T$. gondii $(n=10), T_{2}$ group that received tachyzoites of $T$. gondii plus fresh onion juice 1cc per rat daily by gavages method $(n=10)$, and T3 group which received fresh onion juice 1cc per rat daily by gavage method $(n=10) .30$ days after inducing toxoplasma, 5cc blood were collected for measuring testosterone. Testes tissues of rats in all groups were removed; then, they were prepared for sertoli cells analysis. Serum total testosterones and sertoli were significantly decreased in groups that were infected with $T$. gondii, in comparison to control and onion groups. Moreover, comparing to control group $(p<0.05)$, testes weights in toxoplasma group were drastically decreased. Since, in our study, T.gondii had grave effect on serum total testosterones, and because of applying fresh onion juice led to removing this harmful effect, it is suggested that eating of onion is useful in infected men.
\end{abstract}

Key words: Allium cepa, testes, testosterone, Toxoplasma gondii.

\section{INTRODUCTION}

Toxoplasmosis is a parasitic disease caused by the protozoan Toxoplasma gondii (Ryan and Ray, 2004). The parasite affects most genera of warm-blooded animals, including humans, but the primary host is the felid (cat) family. Although, cats are often blamed for spreading toxoplasmosis, contacting with raw meat is a more significant source of human infections in many countries, and fecal contamination of hands is a greater risk factor (Torda, 2001). Up to one third of the world's human population is estimated to carry a Toxoplasma infection (Montoya and Liesenfeld, 2004). The centers for disease control and prevention noted that the overall seropreva-

\footnotetext{
${ }^{*}$ Corresponding author. E-mail: arashkhaki@yahoo.com.
}

lence in the United States, as determined with specimens collected by the National Health and Nutritional Examination Survey (NHANES) between 1999 and 2004, was found to be $10.8 \%$, with $11 \%$ seroprevalence among women of childbearing age (15 to 44 years) (Jones et al., 2007).

Several conditions can interfere with spermatogenesis and reduce sperm quality and production. Factors such as drug treatment, chemotherapy, toxins, infections, air pollutions, insufficient vitamins intake, and parasites like $T$. gondii tachyzoites, have harmful effects on spermatogenesis and sperm's normal production (Mosher and Pratt, 1991; Santana et al., 2010). Several studies have reported that antioxidants and vitamins A, B, $\mathrm{C}$, and $\mathrm{E}$ can protect sperm's DNA from free radicals, and also, increase barrier stability of blood testis (Jedlinska- 
Table 1. The effect of $1 \mathrm{cc}$ fresh onion juice/rat on sperm parameters, testosterone, apopetosis, and testis weight of control and T. gondii groups.

\begin{tabular}{|c|c|c|c|c|}
\hline Groups & Control & $1 \mathrm{cc}$ fresh onion juice /rat & T. gondii & T. gondii plus, $1 \mathrm{cc}$ fresh onion juice /rat \\
\hline Testis (g) & 1.390 .55 & $1.38 \quad 0.54$ & $10.55^{\star}$ & $1.20 \quad 0.55$ \\
\hline Sertoli cells apopetosis & 50.110 .11 & $61.220 .33^{*}$ & $40.010 .55^{\star}$ & $44.334 .43^{*}$ \\
\hline Testosterone (ng/ml) & 1.220 .11 & $2.460 .11^{*}$ & $0.870 .11^{*}$ & 0.11 \\
\hline
\end{tabular}

( $g=$ gram, $\mathrm{ng}=$ nanogram, $\mathrm{ml}=$ milliliter). Data are presented as mean $\pm \mathrm{SEM}$. *Significant difference at $\mathrm{p}<0.05$ level, (compared with control group).

krakowska et al., 2006). Evidence suggests that Allium cepa (onion juice) has antioxidative and androgenic other important molecules from oxidation and damage, improve sperm quality, and consequently, increase fertility rate in men (Yang et al., 2006). Therefore, the role of nutritional and biochemical factors in reproduction and sub-fertility treatment is very important. The present study was planned to assess the ability of $A$. cepa to promote sertoli cells parameters and testosterone concentration in $T$. gondii infected rats. The results obtained will provide further insights into appropriate treatment of infertile male patients using herbals to improve spermatogenesis.

\section{MATERIALS AND METHODS}

\section{Preparation of onion juice}

The underground yellowish-white bulbs of $A$. cepa (onion) were collected in August 2007 from Ilkhchi in the province of East Azerbaijan-Iran. Before the experiments, the skin was removed and fresh juice of onions was prepared using a Tefal fruit juice extracting machine.

\section{Analysis of onion juice}

The onion juice was tested to determine flavonoids using the Shinoda test (Yousef, 2005). Qualitative thin-layer chromatography (TLC) was employed for determining quercetin as a main flavonoid in onion. For TLC, $10 \mathrm{~mL}$ of fresh onion juice were dried in a vacuum and the resulting residue dissolved in $1 \mathrm{~mL}$ of methanol. 20 $\mathrm{mL}$ of methanolic solution were spotted on a silica gel plate $(10 \times$ $20 \mathrm{~cm}$, silica gel 60 GF254, Merck, Darmstadt, Germany) with a solvent system of EtOAc/MeOH (80:20). Quercetin, Sigma chemical Co. (St. Louis, MO, USA), was used as a control. After developing and drying, the TLC plate was sprayed with a $2 \% \mathrm{AICl}$ solution in methanol. Quercetin in the onion samples appeared as a yellow spot at $\mathrm{RF}=0.6$. Separation of quercetin was performed with further purification by preparative TLC on silica gel; quantitative determination of quercetin carried out on a Model 2100 Spectrophotometer (Shimadzu, Japan) in $370 \mathrm{~nm}$ comparing to a pure quercetin standard curve. The amount of quercetin in fresh onion was found to be $12 \mathrm{mg} / 100 \mathrm{~g}$ (Khaki etal., 2009).

\section{T. gondii infection}

T. gondii strain $\mathrm{RH}$ was maintained by passage in mice every 2 days. Tachyzoites were collected from the peritoneal cavity of infected mice and used to inoculate rats. The rats were intraperitoneally injected with 107 tachyzoites of $T$. gondii at the Department of Veterinary Pathology, Islamic Azad University, Tabriz Branch-Iran (Berdoy et al., 2000). effects in rats, and can promote spermatogenesis cycle (Khaki et al., 2009). Antioxidants protect DNA and

\section{Experimental animals}

Adult Wistar albino male rats $(n=40)$ were included in the present study. The rats were 8 weeks old and weighing $250 \pm 10 \mathrm{~g}$. They were obtained from animal facility of Pasture Institute of Iran. Male rats were housed in rooms with controlled temperature $\left(25^{\circ} \mathrm{C}\right)$, constant humidity (40-70\%), and $12 \mathrm{~h} / 12 \mathrm{~h}$ light/ dark cycles prior to experimental protocols. All animals were treated in accordance with the Principles of Laboratory Animal Care[NIH]. All rats were fed with a standard diet and water. The daily intake of water was monitored at least one week prior to the start of treatments in order to determine the amount of water needed fire very experimental animal. Thereafter, the rats were randomly divided into control $(n=10)$ and experimental $(n=30)$ groups. The control group just received 4cc distilled water daily. However, the experimental infected rats $(n=20)$ were split into two infected $T$. gondii groups; one of these groups was T. gondii test group $(n=10)$ and the other was $T$. gondii group $(n=10)$ received $1 \mathrm{cc}$ of fresh onion juice daily. The fourth experimental group $(n=10)$ received 1cc of fresh onion juice daily (Khaki et al., 2009) this group was onion test group. At the end of the study, the rats were killed by carbon dioxide.

\section{Surgical procedure}

In the thirtieth day, the Pentobarbital sodium $(40 \mathrm{mg} / \mathrm{kg}$ ) was administered intra peritoneal for anesthesia, and the peritoneal cavity was opened through a lower transverse abdominal incision. Then, testisin control and experimental groups was immediately removed. The weights of testis in each group were registered. The animals were decapitated between 9:00 AM and 11:00 AM, and blood samples were obtained. Blood samples were centrifuged at $4^{\circ} \mathrm{C}$ for $10 \mathrm{~min}$ at $250 \mathrm{~g}$, and the serum obtained was stored at $-20^{\circ} \mathrm{C}$ until the time it was assayed.

\section{Statistical analysis}

To compare data in control and experimental groups, ANOVA test was applied. The results were expressed as mean \pm S.E.M (standard error of measurements). Significant differences are written in parentheses.

\section{RESULTS}

\section{Weight of individual male testis}

The obtained results in this study are illustrated in Table 1. There was significant difference in testes weights 
between $T$. gondii groups, as compared to the other groups $(\mathrm{p}<0.05)$.

\section{Results of testosterone levels}

Levels of testosterone were significantly increased in fresh onion juice group comparing to control and $T$. gondii groups $(p<0.05)$. This result is higher in infected rats with $T$. gondii that received $1 \mathrm{cc}$ fresh onion juice, as compared to T.gondii group.

\section{DISCUSSION}

T. gondii infection is associated with a wide spectrum of clinical pictures in men. Onion and garlic contain a wide variety of phytochemicals and micro constituents, such as trace elements, vitamins, fructans, flavonoids and sulphur compounds, which may have a protective effect against free radicals. The present results clearly indicate that A. cepa (onion) has a good effect on spermatogenesis in rats. Our results showed that administration of onion juice (1 $\mathrm{g} / \mathrm{rat} /$ day) for 20 consecutive days caused a marked increase in sperm number, viability, and mobility, as compared to respective controls; this agrees with our previous research (Khaki et al., 2009). These effects could be related to vitamins, vitamin $\mathrm{C}$, and flavonoids of onion such as quercetin. Oxidative damage was as certained by measuring malondialdehyde levels, reactive oxygen species (ROS) generation, alterations in antioxidant defences, and the extent of protein oxidation. Quercetin, an important flavonoid, has a beneficial effect on health due to its antioxidant function. Studies on the effect of quercetin on oxidative damage in cultured chicken spermatogonial cells showed that quercetin has no deleterious effect on spermatogonial cells at doses of 1 and $10 \mathrm{mg} / \mathrm{mL}$. Quercetin (1 $\mathrm{mg} / \mathrm{mL})$ increased the number of spermatogonial cells and decreased the mortality of Aroclor-induced oxidative damage. In this study, the effect of quercetin on serum MDA was determined, but the results indicated no obvious effect of quercetin on MDA production (Mi and Zhang, 2005; Mi et al., 2007). In the present study, $T$. gondii significantly reduced sperm amount and mobility; on the other hand, our research showed that onion fresh juice can enhance both the number of sperm and mobility in group of animals infected with $T$. gondii. These results are in agreement with other finding. They showed that Toxoplasma infection was related to infertility, so it was possibly related to the antisperm antibodies being involved in the pathogenesis of infertility (Zhou et al., 2002; Aral et al., 2011). In their study regarding to mice, Sun et al. (2008) reached to the same results. These researchers found out that acute $T$. gondii infection affects the reproductive function of male mice.
$T$. gondii infections have the ability to change the behavior of rats and mice, making them drawn to, rather than fearful of, the scent of cats. This effect is advantageous to the parasite, which will be able to sexually reproduce if its host is eaten by a cat (Berdoy et al., 2000). The infection is highly precise, as it does not affect a rat's other fears such as the fear of open spaces or of unfamiliar smells. Studies have also shown behavioral changes in humans, including slower reaction times and a six fold increased risk of traffic accidents among infected males (Flegr et al., 2002), as well as links to schizophrenia, such as hallucinations and reckless behavior.

\section{Conclusion}

In our study, $T$. gondii had a significant effect on sperm parameters and serum total testosterones. On the other hand, freshly prepared onion juice significantly affected the sperm number, percentage of viability, and mobility. Onion juice can both reduce and treat this malevolent effect, so it is suggested that eating of onion is useful in infected men.

\section{Acknowledgment}

Many Thanks for Women's Reproductive Health Research Center, Tabriz University of Medical Sciences about its financial support this paper was written according Elham ghadmkheir M.D degree thesis.

\section{REFERENCES}

Aral Akarsu G, Elhan HA, Akarsu C (2011). Retrospective evaluation of Toxoplasma gondii seropositivity in fertile and infertile women.Mikrobiyol. Bul. 45(1):174-80.

Berdoy M, Webster JP, Macdonald DW (2000). Fatal attraction in rats infected with Toxoplasma gondii. Proc. Biol. Sci. 267(1452):15911594.

Flegr J, Havlíček J, Kodym P, Malý M, Šmahel Z (2002). Increased risk of traffic accidents in subjects with latent toxoplasmosis: A retrospective case-control study. BMC Infect. Dis. 2:11.

Jedlinska-Krakowska M, Bomba G, Jakubowski K, Rotkiewicz T, Jana B, Penkowski A (2006). Impact of oxidative stress and supplementation with vitamins $E$ and $C$ on testes morphology in rats. J. Reprod. Dev. 52:203-209.

Jones JL, Kruszon-Moran D, Sanders-Lewis K, Wilson M (2007). Toxoplasma gondii infection in the United States, 1999-2004, decline from the prior decade. Am. J. Trop. Med. Hyg. 77(3):405-410.

Khaki A, Fathiazad F, Nouri M, Khaki AA, Khamenehi HJ, Hamadeh M (2009). Evaluation of androgenic activity of Allium cepa on spermatogenesis in the rat. Folia Morphol(Warsz). 68(1):45-51.

Mi Y, Zhang C (2005). Protective effect of quercetin on Aroclor 1254induced oxidative damage in cultured chicken spermatogonial cells. Toxicol.Scien. 88:545-550.

Mi Y, Zhang C, Taya K (2007). Quercetin protects spermatogonial cells from 2,4-d-induced oxidative damage in embryonic chickens. J Reprod. Dev. 53:749-754.

Montoya J, Liesenfeld O (2004). Toxoplasmosis. Lancet. 363(9425):1965-1976. 
Mosher WD, Pratt WF (1991). Fecundity and infertility in the United States: Incidence and trends. J. Fertil. Steril. 56:192-193.

Ryan KJ, Ray CG (2004). Sherris Medical Microbiology(4th ed.). McGraw Hill Inc., New York pp. 723-727.

Santana LF, Costa AJ, Pieroni J, Lopes WD, Santos RS, Oliveira GP, Mendonça RP, Sakamoto CA (2010). Detection of Toxoplasma gondii in the reproductive system of male goats. Rev. Bras. Parasitol. Vet. 19(3):179-182.

Sun LH, Fan F, Wang JJ, Gong J (2008). Acute Toxoplasma gondii infection affects the reproductive function of male mice. Zhonghua. Nan. Ke. Xue. 14(1):55-57.

Torda A (2001). Toxoplasmosis. Are cats really the source? Aust. Fam. Phys. 30(8):743-747.
Yang HS, Han DK, Kim JR, Sim JC (2006).Effects of alpha- tocopherol on cadmium-induced toxicity in rat testis and spermatogenesis. J. Korean Med. Sci. 21:445-451.

Yousef Ml (2005). Protective effect of ascorbic acid to enhance reproductive performance of male rabbits treated with stannous chloride. Toxicol. 207:81-89.

Zhou YH, Lu YJ, Wang RB, Song LM, Shi F, Gao QF, Luo YF, Gu XF, Wang $P$ (2002). Survey of infection of Toxoplasma gondii in infertile couples in Suzhou countryside. Zhonghua. Nan. Ke. Xue. 8(5):350352. 